\title{
OS DILEMAS DO MARXISMO LATINO-AMERICANO NAS OBRAS DE CAIO PRADO JR. E JOSÉ CARLOS MARIÁTEGUI
}

\section{André Kaysel}

\section{Introdução}

Como as demais ideologias e teorias sociais europeias, o marxismo, ao ser trazido para a América Latina - a partir de fins do século XIX -, defrontou-se com o dilema da distância entre a nova realidade histórica a ser interpretada e seus pressupostos fundamentais, pensados à luz do capitalismo avançado da Europa ocidental. Talvez o já bastante discutido problema do "lugar das ideias", para o caso do liberalismo, seja ainda mais radical no caso do materialismo histórico, dada a reivindicação originária de um vínculo entre teoria e prática. Em outras palavras, se, para Marx, o mundo deveria ser conhecido para ser transformado, o sucesso da ação política revolucionária dependeria da capacidade de interpretar adequadamente a realidade social que se quer transformar.

Artigo recebido em 18/02/2011

Aprovado em 01/12/2011
Quais as razões dessa dificuldade? Para os gramscianos argentinos José Aricó e Juan Carlos Portantiero, ela se deve à singularidade dos processos de formação do Estado e da sociedade na América Latina. Enquanto Marx pressupunha a determinação do Estado pela base social, na América Latina do século XIX a constituição do Estado teria precedido e condicionado a sociedade em formação (Aricó, 1982). Contudo, segundo os autores argentinos, isso não faria da América Latina um caso "oriental", no sentido proposto por Gramsci, para o qual, no Oriente o Estado era tudo e a sociedade civil, débil e gelatinosa. Recorrendo a essa tipologia gramsciana de "Ocidente/Oriente", Portantiero (1978) afirma que a América Latina seria um "outro Ocidente" ou um "Ocidente periférico". De um modo similar, o brasileiro Carlos Nelson Coutinho (1985) sugere que as sociedades latino-americanas seriam casos intermediários entre os dois polos. 
Esse pressuposto teórico da precedência da sociedade civil sobre o Estado teria conduzido os partidos de orientação marxista, socialistas e comunistas, a uma visão societária da política que dificultou a apreensão da importância do Estado na articulação das sociedades latino-americanas, fracamente diferenciadas e bastante hierarquizadas. Daí que as organizações de esquerda inspiradas no marxismo tiveram grandes dificuldades de se implantar solidamente nas massas trabalhadoras, as quais se identificaram muito mais com outro tipo de ator político: os movimentos populistas.

Os diversos populismos que marcaram a história latino-americana ao longo do século XX souberam, muito mais do que o socialismo de inspiração marxista, compreender o tipo de relação que as massas populares estabeleciam com o Estado por meio da figura do caudilho personalista. Mais do que isso, conseguiram, nas palavras de Portantiero, "fundir demandas de classe, demandas de nação e demandas de cidadania num único movimento que recolhia a visão paternalista e caudilhista da concepção tradicional da política” (1985, p. 58).

Essa última passagem é interessante, pois aponta como os movimentos populistas, ao seu modo, foram mais hábeis do que as organizações marxistas ao formular a questão nacional em termos que fizessem sentido para as realidades sociais latino-americanas. Desse modo, teria faltado, ao marxismo clássico, uma chave interpretativa para compreender os termos específicos da questão nacional no subcontinente. Se na Europa o problema nacional se expressou por meio da reivindicação de autonomia ou independência de grupos étnico-linguísticos particulares, na América Latina, este estaria no caráter inconcluso do processo de constituição das nações, isto é, na não incorporação de grandes parcelas da população à vida econômica, social e política dos Estados da região.

O objetivo deste artigo é comparar a relação entre o marxismo e a questão nacional em duas obras que procuraram adequar o marxismo à realidade latino-americana: as do historiador brasileiro Caio Prado Jr. (1907-1990) e as do jornalista e militante peruano José Carlos Mariátegui (18941930), respectivamente o mais influente intérprete marxista do Brasil e o mais importante marxista da América Latina.

Creio que o interesse em comparar o pensamento dos dois autores não resida em sua influência no debate nacional ou continental, nem mesmo em sua heterodoxia, mas sim porque suas obras apresentam analogias importantes que possibilitam e tornam fecunda a comparação. ${ }^{1}$ Em primeiro lugar, ambos têm como cerne das suas reflexões - tanto como chave de interpretação, quanto como programa político - a questão nacional. Em segundo lugar, ambos abordam a questão nacional de modo análogo: ou seja, como a formação inconclusa da nação, devido à persistência de relaçôes econômicas e sociais legadas pela colônia. Em terceiro lugar, ambos encaravam o materialismo histórico, não como um sistema de categorias a ser aplicado ao real, mas como um método capaz de apreendê-lo de modo original. Por fim, ambos pertenceram ao movimento comunista e ocuparam nele uma posição heterodoxa ou marginal, o que fez com que suas vozes permanecessem relativamente isoladas em seu tempo.

Em que pesem tais aproximações, é importante lembrar que se trata de obras muito diferentes. Como então compará-las? O procedimento aqui adotado será o de cotejar o pensamento de Prado Jr. e de Mariátegui em torno de alguns temas ou questôes comuns: a passagem colônia/nação, a questão agrária, a relação entre o imperialismo e a burguesia nacional, e a teoria da revolução. Ao longo desta análise, procurarei entender as diferenças ou as discrepâncias entre as ideias dos autores com base nos diferentes contextos históricos e locais nos quais foram concebidas. Não me refiro apenas aos contextos nacionais - o Peru dos anos de 1920 e o Brasil entre os anos de 1930 e 1960 -, mas também aos diferentes momentos do movimento comunista nos quais os autores militaram.

Desse modo, a metodologia aqui empregada parte do pressuposto de que o contexto histórico deve ser tratado como elemento interno à obra em estudo (Cândido, 1965). No campo específico da história do pensamento político, a abordagem contextualista mais conhecida é aquela que privilegia a reconstrução dos contextos por meio da linguagem política disponível e da recupera- 
ção das intenções originais dos autores (Skinner, 1974; Tully, 1988).

Embora reconheça a importância da exigência de se partir de uma adequada contextualização histórica, creio que a excessiva ênfase dos adeptos do "contextualismo linguístico" na intencionalidade do autor limita o escopo de questôes para o estudo do pensamento político. Afinal, a exigência de fidelidade às intençôes originais pressupooe uma certa transparência, bastante questionável, do social, além de colocar de lado o problema de como e por que autores do passado são recuperados e re-significados no presente, o que aproxima o estudo das ideias políticas de uma arqueologia sem maior interesse para os dilemas atuais (Femia, 1988; Brandão, 2007). Assim, ainda que partindo da necessidade de uma reconstrução contextual rigorosa, pretendo não me restringir aos limites propostos por Skinner, pois procurarei discutir autores que nunca pretenderam dialogar entre si, ou seja, não compartilharam o mesmo contexto histórico, além de pensar contribuições que estes deixaram para a atualidade.

\section{A colônia como negação da nação}

A primeira e mais evidente discrepância entre Caio Prado e Mariátegui está na caracterização da colônia. Enquanto, para o historiador brasileiro, a colonização portuguesa foi uma empresa mercantil e escravista, para o peruano, a colônia espanhola foi uma transplantação do feudalismo, em declínio na Europa, que rompeu com o "comunismo primitivo" que caracterizaria o Império Inca (Prado Jr., 1957, pp. 13-26; Mariátegui, 2008, pp. 7-8)

Tal divergência se explica tanto por motivos geracionais, como pelas óbvias diferenças entre os dois processos de colonização. Caio Prado fez parte de uma geração de historiadores que, a partir dos anos de 1940 e por motivos que discutirei adiante, fez uma revisão historiográfica que questionou o uso do conceito de feudalismo para interpretar a realidade latino-americana. Já Mariátegui, viveu em uma época em que esse uso, dentro e fora do marxismo, era consensual.
Por outro lado, é inegável que o uso de caracterizações como mercantil ou feudal se baseiam também em condições concretas dos dois casos. Em outras palavras, se a escravidão e o sistema de plantation estão muito distantes do feudalismo, a encomienda ou a versão colonial da mita - nas quais o trabalho é compulsório mas o camponês não é propriedade do senhor - estão mais próximas. É interessante notar que, ao justificar a rejeição ou a adoção do conceito de feudalismo, ambos procuram se reportar, seguindo o método de Marx, às relações de produção (Prado Jr., 2002, p. 175; Mariátegui, 1991a, p. 109).

Essa divergência de leitura não impede que os dois autores tenham uma visão similar do papel histórico da colônia. Em ambos os casos ela funciona como negação da nação. Para Caio Prado, por ser a sociedade colonial uma empresa voltada para os mercados externos e baseada no trabalho escravo, estariam ausentes os pressupostos básicos de uma nação: uma estrutura econômica dirigida a partir "de dentro" e voltada para o atendimento das necessidades de sua população.

Aliás, o historiador identifica na condição mercantil e escravista a origem de um contingente populacional livre, mas despossuído, o qual ficaria sem um lugar na produção. Esse setor, que Prado Jr. (1957, pp. 267-297) denomina "inorgânico", seria um elemento constante de crise na ordem colonial por esta não poder absorvê-lo. A mera existência do setor inorgânico anunciaria, pois, a virtualidade da nação. Já Mariátegui, ao pensar a colônia como ordem feudal que submete os indígenas ao domínio espanhol, aponta aí uma fratura histórica entre o elemento colonizador e o colonizado, o que impediria as diversas partes da formação social de se integrarem numa nação:

O problema está nas raízes mesmas deste Peru, filho da conquista. Não somos um povo que assimila as ideias e os homens de outras nações, impregnando-os de seu sentimento e seu ambiente e consegue, desta sorte, enriquecer sem deformá-lo, seu espírito nacional. Somos um povo no qual convivem, sem fundir-se, sem se entender ainda, o índio e o branco conquistador (Mariátegui, 2008, p. 86). 
Para tanto, seria preciso romper com essa fratura, incorporando o índio à vida econômica, social e política, tornando-o, enfim, a base da nacionalidade.

\section{Os processos de independência}

Dito isso, caberia a pergunta: por que as relações coloniais não foram definitivamente superadas? A resposta, para ambos os autores, estaria na forma pela qual se deram os processos de emancipação política no Brasil e no Peru.

Já se disse anteriormente que a questão nacional é o cerne tanto da obra do brasileiro como da do peruano. Mais do que isso, ambos a trabalharam de modo similar: tratava-se de captar a dialética entre colônia e nação, na qual a nação em processo de formação - fruto da crise do regime colonial era negada pelas estruturas legadas pela colônia, as quais se renovavam e se reforçavam com o avanço da integração dessas economias no sistema capitalista. Dessa maneira, ganham relevo as leituras dos dois autores a respeito do processo de independência de seus países.

Caio Prado, em seu ensaio de estreia analisa como, no período de quarenta anos que vai da vinda da família real (1808) até a Revolução Praieira (1848), os conflitos entre a burguesia mercantil lusitana e os proprietários de terra brasileiros trouxeram para o palco da luta política tanto os homens livres sem posses, como os escravos, em especial nas revoltas do período regencial. $\mathrm{Na}$ opinião do autor, a "inorganicidade" dessas massas populares - as quais não foram capazes nem de se unir, nem de se emancipar da liderança das elites regionais - permitiu a reação conservadora (1837-1840) e a consolidação de um Estado centralista e calcado na escravidão (Prado Jr., 1987 , pp. 48-79).

Já Mariátegui enfatiza como a participação subordinada das massas mestiças e indígenas no processo de independência, comandado pela aristocracia feudal, marcou os limites da emancipação política. Além disso, a distância entre o Peru e os centros do mercado mundial teria retardado ainda mais o desenvolvimento capitalista do país, consolidando a persistência das antigas relações de produção (Mariátegui, 2008, pp. 9-13). Enfim, tanto para o brasileiro, como para o peruano, se a emancipação política abriu caminho para a construção da nação, esse caminho ficou bloqueado pelo fato de as classes dominantes - que lideraram o processo - terem reforçado as estruturas sociais do período anterior. Tratava-se, pois, de revoluções burguesas incompletas.

Caio Prado e Mariátegui procuraram captar um processo histórico no qual as rupturas eram incompletas ou inexistentes, onde o passado se repunha sob novas formas, onde arcaico e moderno se articulavam e se potencializavam reciprocamente. Desse modo, a consolidação de uma nação socialmente integrada - segundo os padrões legados pela Revolução Francesa - seria alcançada por meio de uma ruptura radical com um passado colonial, o que implicaria em uma mudança da posição dos respectivos países na ordem econômica internacional.

Pode-se retomar o rico paralelo que Carlos Nelson Coutinho traçou entre a visão de Caio Prado sobre a formação social brasileira e os conceitos de "revolução passiva" (Gramsci, 2002a, pp. 65-85) e de "via prussiana” (Lênin, 1986, p. 406). Embora com importantes limitações teóricas, ${ }^{2}$ o historiador paulista pôde - como o marxista italiano ou o russo - empregar o método de Marx e Engels de modo criativo para entender um processo de "via não clássica para o capitalismo". Tal processo seria caracterizado, não por uma ruptura revolucionária, mas sim pela ausência de transformaçôes mais radicais e pela permanência de uma estrutura social e política herdada do passado. Como afirma o mesmo Coutinho, o outro autor latino-americano a realizar uma empreitada similar foi justamente José Carlos Mariátegui (1989, pp. 116-132. É essa perspectiva comum que possibilita aproximar o brasileiro do peruano.

\section{Duas vias “não clássicas” para o capitalismo}

É o caso agora de aprofundar no que consistiria, para cada autor, a "via não clássica" para o capitalismo, nas reflexões realizadas acerca de suas respectivas formaçôes sociais. Empreende- 
rei essa análise por meio de dois temas presentes em ambos os pensadores de modo entrelaçado: a questão agrária e a relação entre imperialismo e burguesia local. Assim como no caso da conceituação da colônia, o modo pelo qual os dois autores abordam suas respectivas formações econômico-sociais e a questão agrária que delas emerge é marcadamente diferente.

Enquanto o historiador brasileiro centra-se no conflito entre o capital agro-mercantil e a força de trabalho, considerando o campesinato e suas reivindicaçôes de acesso à terra problemas secundários ou residuais, Mariátegui, por seu turno, pensa em termos de um conflito entre um campesinato indígena, lutando pela terra, e uma elite feudal de origem criolla $^{3}$ (Prado Jr., 2000, pp. 15-85; Mariátegui, 2008, pp. 26-38). Quais fatores explicam essas diferenças? Ensaiarei duas possibilidades de explicação complementares. De um lado, uma que remeta às diferenças entre a sociedade brasileira e a peruana e, de outro, a remissão aos contextos intelectuais e políticos distintos nos quais os autores produziram suas obras.

Quanto à primeira explicação, creio que o divisor de águas esteja no tema, central para os dois intelectuais, das relações sociais de produção. Caio Prado pode rejeitar - com base no vínculo originário entre escravidão, grande propriedade e produção para o mercado exterior - a existência de um passado feudal, além de sustentar a escassez de um autêntico campesinato (Prado Jr., 1957, pp. 113-123). Já Mariátegui tinha diante de si a sobrevivência do ayllú - comunidade rural indígena baseada na apropriação e no trabalho coletivos e a persistência de relações de trabalho originadas nas encomiendas, as quais eram mais próximas da servidão do que da escravidão, uma vez que o camponês, ainda que submetido ao trabalho compulsório, não era propriedade do senhor (Mariátegui, 2008, pp. 9-10).

Ainda que se possa fazer objeções às interpretaçôes dos dois autores a respeito das relaçôes de trabalho no campo em seus países, é preciso admitir que a grande propriedade rural brasileira esteve sempre articulada ao mercado externo, ao passo que no Peru, pela colonização ser centrada na mineração, o latifúndio do altiplano voltava-se mais para "dentro" e era pouco mercantil (Donghi, s.d., pp. 11-63). Assim, as próprias diferenças entre o campo no Brasil e no Peru ajudam a entender os distintos diagnósticos da questão agrária.

Não deixa de ser curioso que os próprios textos parecem apoiar essa análise ao confirmarem, coincidentemente, um o argumento do outro. Caio Prado, por exemplo, em uma das inúmeras passagens em que aponta a escassez de um autêntico campesinato brasileiro, por meio de uma longa nota, compara o sistema da grande exploração com os casos dos países andinos e do México, nos quais as populações autóctones constituiriam uma classe camponesa, expropriada pelo colonizador espanhol e, portanto, aspirariam objetivamente ao acesso à terra (Prado Jr., 1966, pp. 221-222).

Se essa nota de $A$ revolução brasileira converge, inadvertidamente, com o raciocínio de Mariátegui sobre o problema agrário no altiplano, este último parece dar razão ao primeiro ao negar a conveniência de se parcelar as grandes empresas agrícolas da costa peruana. A justificativa de Mariátegui é a de que, parcelados, esses latifúndios perderiam seu caráter de empresas orgânicas trabalhadas coletivamente, argumento este muito próximo, portanto, daquele empregado por Caio Prado para a grande exploração no Brasil (Mariátegui, 1991a, p. 114).

Todavia, se o feudalismo era mais próximo das estruturas agrárias do Peru do que das do Brasil, isso não é suficiente para explicar o porquê de um autor defender o caráter feudal das relações sociais do campo, ao passo que o outro afirmava serem elas mercantis. Essa discrepância só pode ser mais bem compreendida tendo-se em mente as diferenças históricas entre os contextos intelectuais de cada um. Até o início dos anos de 1930, não apenas a interpretação de um passado colonial feudal era hegemônica no pensamento social latino-americano, como a própria questão da articulação entre os países da região e o sistema capitalista havia apenas começado a se constituir como um problema de reflexão. Com a crise do modelo agroexportador e da dominação oligárquica - que tem a Primeira Guerra Mundial e a crise de 1929 como principais marcos -, o lugar da América Latina no conjunto do mercado mundial se torna um problema político e teórico (Funes, 2006, pp. 224-226). 
Mariátegui produziu sua obra justamente entre a guerra e a crise, e tomou o caráter colonial da economia de seu país como um tema-chave; no entanto, continuava dominante o paradigma do feudalismo. Já Caio Prado, escrevendo após 1930 e num ambiente intelectual que preparava o terreno para o debate sobre o desenvolvimento, encontrou condiçōes para superar a noção de feudalidade por meio da inserção da trajetória da formação social brasileira no interior do mercado mundial. ${ }^{4}$ No período após 1945 , quando o historiador brasileiro já havia consolidado sua interpretação historiográfica inovadora sobre o Brasil-colônia e sua crise, foi fundada a Comissão Econômica para a América Latina e Caribe (Cepal), organismo no qual intelectuais iriam desencadear e pautar todo o debate sobre o desenvolvimento. Celso Furtado - ao lado de Raúl Prebisch, o principal pensador da Cepal - também irá considerar, em Formação econômica do Brasil (1959), a estrutura econômica brasileira como sendo integrada ao mercado internacional desde sua origem (Furtado, 1962, pp. 5-8). Nessa nova fase histórica - conhecida hoje como desenvolvimentista -, Caio Prado teria como interlocutores não apenas os intelectuais comunistas que se aferravam à tese dos "restos feudais", mas também os intelectuais cepalinos, como Furtado.

O que importa assinalar aqui é que as novas condiçôes históricas em que se encontravam o Brasil e a América Latina, nas quais a economia primário-exportadora e a dominação oligárquica haviam entrado em crise definitiva, e a industrialização aparecia como alternativa de superação do atraso, traziam novas questões aos intelectuais latino-americanos. ${ }^{5}$ Nesse novo cenário, Caio Prado ao lado do argentino Sérgio Bagú e do chileno Marcelo Segall - pôde ser um dos pioneiros no interior do marxismo a rejeitar a tese do feudalismo colonial, revelando o caráter mercantil e escravista da colônia. Quanto a Mariátegui, não se pode exigir de um intelectual que responda questôes que seu tempo histórico não permite. Se a articulação subordinada da economia peruana ao capitalismo mundial e seus efeitos internos foi um tema crucial da reflexão mariateguiana, reavaliar a caracterização das relaçôes sociais do campo, à luz dessa articulação não estava em seus horizontes.
Todavia, é justamente no tema da inserção subordinada das formações sociais respectivas no capitalismo internacional que se pode encontrar uma das principais convergências entre os autores estudados. Lembre-se, por exemplo, a passagem dos Siete ensayos... sobre "o caráter colonial" do latifúndio da costa (Mariátegui, 2008, pp. 80-81). A maneira pela qual Mariátegui demonstra como os cultivos da costa peruana derivam dos interesses dos mercados metropolitanos de Londres e Nova York tem fortes semelhanças com a noção caio-pradiana de "sentido da colonização" como origem e dinâmica da grande exploração. Em ambos os casos se apontam como os interesses mercantis externos determinam o desenvolvimento de certas atividades produtivas, além de condicionarem sua estrutura, ritmos de ascensão e crise. Desse modo, tanto o brasileiro como o peruano deram destaque aos efeitos que a dominação econômica estrangeira exercia sobre as estruturas socioeconômicas internas, independentemente dos conceitos que empregavam para definir tais estruturas.

\section{O imperialismo e a burguesia nacional}

Essa constatação introduz a necessidade de abordar o tema do imperialismo e suas relações com as classes dominantes locais. Aqui, é preciso fazer referência ao interlocutor comum aos dois intelectuais: o movimento comunista. A Internacional Comunista (IC) colocava como problemas fundamentais dos países "coloniais, semicoloniais e dependentes", de um lado, a persistência de restos feudais e, de outro, a dominação imperialista como travas do desenvolvimento capitalista dessas sociedades. Segundo essa formulação - elaborada originalmente para o caso da China e posteriormente generalizada para o conjunto da periferia do capitalismo (Schlessinger, 1974, pp.43-53; Caballero, 1988, pp. 121-145) -, haveria solidariedade entre os interesses imperialistas e dos latifundiários feudais. Tanto Caio Prado como Mariátegui se inserem no seio dessa vertente político-intelectual ao também enquadrarem os problemas centrais de suas formaçôes econômico-sociais em torno da questão agrária e do imperialismo. 
Contudo, como se verá adiante, as formulações de ambos sobre o imperialismo e sua relação com as classes dominantes em seus países discrepa daquela defendida pela ortodoxia comunista. Se para esta, a burguesia nacional, assim como o proletariado, teria um interesse objetivo em combater tanto os restos feudais, como o capital imperialista, Caio Prado e Mariátegui não enxergavam as coisas desse modo. Pelo contrário, viam com ceticismo o papel histórico que as burguesias brasileira ou peruana poderiam ter no combate à dominação econômica estrangeira, uma vez que sua origem estaria vinculada à inserção subordinada dessas economias no sistema capitalista internacional.

Nesse sentido, é bom lembrar que os dois procuraram desconstruir o modelo que a IC tentava impor à região - decalcado da experiência da Revolução Chinesa durante os anos de 1920 -, demonstrando o modo diferente pelo qual o imperialismo se articulava com as burguesias locais na América Latina e na Ásia. Em "Punto de Vista Anti-Imperialista" - tese enviada com a delegação peruana à I Conferência Comunista Latino-americana, realizada em Buenos Aires, em junho de 1929 -, Mariátegui começa por propor uma diferenciação interna entre os chamados países "semicoloniais". De um lado, haveria aqueles que vivenciariam a intervenção política e militar direta do imperialismo, o que, por conseguinte, levaria a burguesia e a pequena-burguesia a assumir uma postura nacionalista ou anti-imperialista. De outro, haveria países nos quais, em que pese o caráter semicolonial da economia, a burguesia se sentiria suficientemente "dona do poder político" para não se preocupar com a soberania nacional, associando-se ao capital estrangeiro sem reservas (Mariátegui, 1991b, p. 202).

Haveria ainda diferenças de caráter cultural. $\mathrm{Na}$ China, por exemplo, tanto o nobre como o burguês se sentiriam imbuídos de um sentimento nacional que os oporia ao estrangeiro e os vincula ao povo. Já na Indo-América: "a aristocracia e a burguesia criollas não se sentem solidárias com o povo por laços de uma história e cultura comuns. No Peru, o aristocrata e o burguês brancos desprezam o nacional [...]. O pequeno-burguês mestiço imita esse exemplo" (Idem, p. 204).
Dentro da América Latina também se reproduziria essa divisão. De um lado, na América Central - cujas Repúblicas tinham a experiência da intermitente intervenção militar norte-americana poderiam se desenvolver movimentos cujo eixo seria o anti-imperialismo e a libertação nacional. De outro, na América do Sul, cujas burguesias não se sentiam ameaçadas pelo imperialismo, o anti-imperialismo só poderia ser coerentemente sustentado por movimentos classistas (Idem, p. 206).

Aqui é importante lembrar que o alvo imediato de Mariátegui não era a $\mathrm{IC}$, mas sim seu conterrâneo Victor Raúl Haya de la Torre, político nacional-populista, fundador da Aliança Popular Revolucionária Americana (Apra). ${ }^{6}$ Para Haya de la Torre, o imperialismo seria a primeira fase do capitalismo na América Latina, ainda parcialmente feudal (2002a, p. 63). Partindo de uma visão evolucionista da história, Haya considerava que os países latino-americanos não podiam prescindir dos aportes técnicos trazidos pelo imperialismo, mas deveriam controlar a tendência dos capitais imperialistas para dominar suas economias (Idem, pp. 64-65). Tal controle seria obtido por meio da construção de um "Estado-anti-imperialista”, apoiado na aliança das classes prejudicadas pela dominação estrangeira - operários, camponeses e a classe média -, cujo primeiro exemplo teria sido o Estado que emergira da Revolução Mexicana (Idem, 2002b, p. 51).

Desse modo, não é a toa que Mariátegui tenha escrito: "Nem a burguesia, nem a pequena-burguesia no poder podem fazer uma política anti-imperialista. Temos a experiência do México, aonde a pequena-burguesia acabou pactuando com o imperialismo yankee" (Mariátegui, 1991b, p. 205).

Embora rejeitasse a heterodoxa visão de Haya de la Torre, a IC não deixava de compartilhar com ele uma interpretação evolucionista do processo histórico. Assim, ao criticar o líder aprista, Mariátegui acabou por atingir a concepção da IC sobre o papel do imperialismo no subcontinente.

Escrevendo quase quatro décadas mais tarde, Caio Prado também enxerga um erro fundamental nas formulações da IC do final do decênio de 1920 sobre o imperialismo. Enquanto na Ásia e na África o imperialismo teria se implantado em sociedades constituídas fora da órbita do capita- 
lismo - gerando, assim, profundas tensōes sociais, políticas, culturais e mesmo étnicas -, as sociedades latino-americanas teriam se constituído a partir da expansão do capitalismo comercial europeu, etapa de formação do capitalismo industrial, ou seja, dentro dos quadros do mercado e da modernidade europeia em formação. Assim, o imperialismo definido como fase contemporânea do capitalismo internacional - teria encontrado aqui um terreno já preparado por estruturas legadas pelo passado colonial (Prado Jr., 1966, pp. 100-102).

Esses dois modos distintos de articulação com o imperialismo resultam em diferentes conformações da burguesia. No primeiro caso, forma-se um setor autóctone vinculado aos interesses comerciais estrangeiros em oposição a outro, interessado no desenvolvimento de uma indústria própria. Já no segundo, os diferentes ramos da burguesia - agrária, comercial, industrial e financeira - desenvolveriam laços de associação com o capital estrangeiro, não tendo assim interesses anti-imperialistas.

Em que pese essa convergência básica, os dois intelectuais marxistas aqui analisados possuem, ao pensar a relação entre o imperialismo e a burguesia, uma discrepância sutil, porém importante. Doze anos antes de escrever $A$ revolução brasileira, curiosamente Caio Prado, ao enumerar os sujeitos sociais das transformaçôes econômicas das quais o Brasil necessitava, inclui, ao lado do proletariado, "a burguesia industrial e comercial, liberta de seu vínculo com o imperialismo" (Prado Jr., 1954, p. 240). Essa referência é tanto mais surpreendente pois não só vai na contramão das formulações consagradas na obra já citada de 1966, como também contraria posições anteriores do autor, tomadas a propósito de polêmicas partidárias (Prado Jr., 2007, p. 140). Como explicar tal oscilação?

Creio que a resposta pode ser encontrada nos artigos escritos pelo autor na Revista Brasiliense a respeito da industrialização e do capital estrangeiro. Se, por volta de 1955, ele se mostrava otimista em relação às potencialidades do nacionalismo brasileiro de conduzir um processo de industrialização autônoma (Prado Jr., 1955, p. 80), logo em seguida condena a opção, feita pelo governo de Juscelino Kubitschek (JK), de promover o desenvolvimento amparando-se no capital estrangeiro (Idem, 1959, p. 6).
É bom lembrar, seguindo Bresser-Pereira (1979, pp. 272-274), que até meados da década de 1950 a batalha pela industrialização ainda não havia sido ganha, havendo importantes parcelas das elites ligadas ao setor primário-exportador que defendiam a velha tese da "vocação agrícola" do Brasil. Em seguida, porém, veio à tona a questão de se a industrialização deveria ser conduzida com base em capitais nacionais ou recorrendo aos estrangeiros.

Assim, se Caio Prado, entre 1954 e 1956, apostou, como fez o Partido Comunista Brasileiro - PCB, na ampla frente social industrializante, num segundo momento, passou a criticar a opção de JK e da maior parte da burguesia pelo recurso aos "capitais imperialistas". Oscilaçōes como essas não podem ser observadas nas leituras de Mariátegui. A razão, mais uma vez, deve ser buscada na diferença entre Brasil e Peru. Os avanços da industrialização e da modernização da economia experimentados pelo Brasil em meados do século XX contrastam com a situação vivida pelo Peru na década de 1920. Ali, o que havia era uma economia de enclave, baseada na mineração, na extração de petróleo e na agricultura comercial. Não havia, então, perspectivas apreciáveis de industrializar o país andino. Assim, Mariátegui, para além de sua concepção do imperialismo e do processo revolucionário, tinha diante de si uma situação na qual uma etapa de desenvolvimento capitalista levado a diante por uma classe burguesa progressista não seria muito realista.

\section{A revolução: programa e agentes}

Essa última discrepância entre as duas obras remete ao último tema comum que articula o cotejo aqui empreendido: o da teoria da revolução. Esta se desdobra em dois planos. Em primeiro lugar, num programa ou tarefas históricas a serem cumpridas e, em segundo, nos sujeitos ou atores sociais que levarão tais tarefas a cabo.

Para o historiador brasileiro, o programa revolucionário adequado ao país deveria centrar-se na conclusão da construção da nação, superando definitivamente as relações coloniais. Esse processo 
dar-se-ia, de um lado, pela generalização de direitos sociais e trabalhistas no campo, o que forçaria a desconcentração da propriedade rural (Prado Jr., 1966, pp. 216-218) e completaria a transição para o trabalho livre, e, de outro, pela consolidação de um mercado interno de massas, que se converteria no motor do desenvolvimento nacional e na superação da a dependência externa (Idem, pp. 256-257). Os sujeitos dessas transformações seriam a classe operária urbana e os trabalhadores rurais, cujos interesses objetivos, embora muitas vezes "sem a devida consciência", convergiriam nesse sentido (Idem, pp. 279-280). Dessa maneira, Caio Prado critica seu partido por ter apostado no caráter progressista e nacionalista da burguesia, a qual o autor via como alinhada aos interesses imperialistas e da grande exploração rural. Desse equívoco, conclui ele, teria resultado o fracasso político da teoria "oficial" da revolução brasileira.

Todavia, essa crítica não implicava na defesa de uma revolução socialista. Na realidade, Caio Prado afirmava que começar o debate sobre a revolução a partir de "rótulos" como "socialista" ou "democrático-burguesa” seria um equívoco teórico, já que uma revolução, para ele, se definiria por suas tarefas históricas (Idem, pp. 3-5). Seja como for, ele é claro ao dizer, em acordo com o PCB, que o socialismo não estaria na ordem do dia do Brasil de então (Idem, pp. 265-266).

É sintomático observar a esse propósito a convergência insuspeita dos dois principais críticos de $A$ revolução brasileira. Assis Tavares (pseudônimo do dirigente pecebista Marco Antônio Tavares Coelho), defendendo a linha do partido, adverte que o programa defendido pelo historiador era vago e estava aquém do programa do PCB (Tavares, 1967, p. 58). Já o trotskista Ruy Fausto aponta na obra um divórcio entre a economia e a política, o que manteria Caio Prado na órbita do "reformismo" de seu partido (Fausto, 1967, pp. 9-10).

Ao contrário do que sustenta a maior parte de seus comentadores, estou de acordo com Gildo Marçal Brandão e Raimundo Santos de que Caio Prado seja um legítimo representante da cultura política pecebista (Brandão, 1997, pp. 219-220; Santos, 2001). Sua teoria da revolução como processo contínuo de reformas é, em realidade, o auge e o limite da elaboração sobre o assunto no interior do marxismo de matriz comunista no Brasil (Brandão, 1997, p. 54).

Mariátegui, como já foi referido, também concordava em que a tarefa histórica central da revolução no Peru seria a de completar a formação da nação e superar a colônia. A concretização desse objetivo dar-se-ia pela solução de dois problemas conjugados: a questão indígena e a questão agrária. Os indígenas seriam incorporados à vida nacional quebrando-se o monopólio da aristocracia feudal sobre a terra (Mariátegui, 1991d, pp. 218220). Para ele, esse programa implicava também a ruptura com o imperialismo, cujo interesse se ligava à ordem vigente. Os portadores sociais dessas transformaçōes seriam a classe operária urbana e os camponeses indígenas (Aricó, 1978, p. xlviii). Ao contrário de Caio Prado, Mariátegui considerava a revolução como sendo claramente socialista. Nesse sentido, o revolucionário peruano não via, na periferia do capitalismo, contradição entre nacionalismo e socialismo. Enquanto na Europa, o nacionalismo adquiria um caráter conservador, nos países coloniais, por não haver cumprido sua missão revolucionária, o nacionalismo desembocaria no socialismo (Mariátegui, 1995, p. 250).

Dado que a burguesia peruana chegara tarde demais à cena histórica e o capitalismo internacional só reservava ao Peru o papel de "semicolônia", as tarefas revolucionárias, em que pese seu "caráter burguês”, só poderiam se realizar por meio do socialismo (Idem, 1991c, p. 127).

Do mesmo modo que na polêmica sobre o imperialismo, o marxista peruano também procurava criticar as concepçôes de Haya de la Torre sobre o processo revolucionário no Peru e na América Latina. Para este último, o objetivo da revolução seria o de criar um "Estado anti-imperialista", apoiado, como já foi dito, em uma aliança policlassista, capaz de assegurar a soberania nacional por meio da implantação de um capitalismo de Estado (Haya de la Torre, 2002b, pp. 56-58).

Mais uma vez, as teses mariateguianas extrapolaram a polêmica com o aprismo e o confrontaram com a ortodoxia da IC, que defendia a precedência de uma etapa "democrático-burguesa" da revolução para os "países semicoloniais". Na realidade, a di- 
vergência de fundo entre o peruano e a IC devia-se ao fato de o primeiro empregar o marxismo como método para apreender a especificidade do Peru e da América Latina, enquanto a última empregava-o como um sistema de categorias universalmente válidas (Mellis, 1978, p. 225).

Examinadas as respectivas concepções do processo revolucionário e as polêmicas que a esse respeito foram travadas pelos autores, cabe verificar as discrepâncias e as convergências entre Caio Prado e Mariátegui a respeito deste tema. Enquanto o peruano afirmava o caráter socialista da revolução, o brasileiro defendia uma revolução definida segundo suas tarefas históricas, que avançasse por meio de reformas sucessivas. Isso não significa que o peruano desprezasse o caráter processual e de longo prazo da revolução ou que o brasileiro não tivesse o socialismo por objetivo último. O que se quer dizer é que, enquanto o primeiro acreditava na necessidade de uma ruptura mais drástica, o segundo defendia um caminho mais gradualista.

A diferença se explica, em grande parte, por razōes históricas. Mariátegui, é bom lembrar, viveu na Europa durante a onda revolucionária que se seguiu à Revolução de 1917 (1919-1923), tendo sido particularmente influenciado pela experiência das agitaçôes operárias do norte da Itália, no que ficou conhecido como "biênio vermelho" (1919-1920), pela fundação do Partido Comunista Italiano (1921) e pela reação fascista (Paris, 1980, pp. 100-121). Além disso, militou em um movimento comunista internacional que, embora com importantes mudanças de estratégia política ao longo da década de 1920, acreditava na proximidade da revolução mundial.

Já Caio Prado, embora tenha sido formado na mesma matriz política, militou em um período mais longo, que vai dos anos de 1930 aos de 1960. Nesse período, em especial após a dissolução do Comintern (1943) e após a Segunda Guerra Mundial, os PCs alinhados com a União Soviética foram adotando - em virtude da Guerra Fria e da estabilização do capitalismo mundial - uma linha mais defensiva e, não sem oscilações, tendente à integração nos sistemas políticos nacionais.

Entretanto, talvez se possa aventar uma explicação complementar, calcada na diferença dos contextos nacionais. O Peru dos anos de 1920, além da ditadura pessoal de Augusto B. Leguía, ${ }^{7}$ caracterizava-se ainda por uma ordem social oligárquica e uma rígida estratificação que seguia linhas étnicas, com a exclusão da massa indígena (Galindo e Burga, 1994), ao passo que o Brasil entre 1930 e 1964 - viveu um processo de incorporação, ainda que subordinada, das classes trabalhadoras urbanas na política. Assim, se no Peru da década de 1920 seria difícil crer em transformaçôes por meio de reformas, no Brasil, especialmente entre o pós-guerra e o golpe de 1964, esse era um caminho plausível.

Outra discrepância entre os autores diz respeito às diferentes formas de articulação entre a leitura que ambos tinham dos processos históricos mais gerais e a análise das conjunturas políticas. Uma das críticas mais contundentes feita, tanto por Assis Tavares, como por Ruy Fausto, a Caio Prado é de sua incompreensão das exigências da análise e da ação políticas. Com base nessa crítica, creio ser possível apontar um certo "economicismo" nas análises políticas empreendidas pelo historiador paulista. Não que suas teses historiográficas fossem economicistas, o que não creio que tenham sido. Aqui o termo "economicismo" tem a acepção dada por Gramsci: a dificuldade de distinguir entre os processos estruturais de longo prazo e o acontecer conjuntural, tendendo-se a reduzir um ao outro (Gramsci, 2002b, pp. 37-38).

O historiador brasileiro procurou derivar de sua concepção do processo de formação da sociedade brasileira um programa alternativo ao do PC, mas sem levar em consideração a necessária mediação das conjunturas políticas. Suas propostas programáticas, além de vagas e gerais, permaneceram nos limites da cultura política comunista de então. Assim, talvez se explique por que, em que pese inovações teóricas para os padrôes da esquerda brasileira de seu tempo, como sua conceituação de revolução, Caio Prado não tenha logrado pensar uma alternativa política à altura de sua contribuição como historiador.

Curiosamente, uma acusação similar foi feita, tanto por Haya de la Torre, como pelo responsável pelo Secretariado Sul-americano da Internacional Comunista (SSAIC) Vittorio Codovilla, a Mariá- 
tegui: a de ser um intelectual insensível às exigências da ação política (Galindo, 1994, p. 480). Essa me parece ser, contudo, uma visão equivocada sobre o marxista peruano. Caso se observe sua conduta durante e após a já mencionada ruptura com o APRA, em 1928, ver-se-á como Mariátegui foi mais capaz do que Caio Prado de articular suas concepções à ação política. A própria fundação do Partido Socialista Peruano (PSP), ainda no mesmo ano, que não estava em seus planos mais imediatos antes do confronto com o aprismo, foi uma tentativa de criar uma organização ao mesmo tempo inserida na órbita da IC e enraizada nas condiçōes concretas do país (Idem, p. 474). Não é possível saber como o autor dos Siete ensayos... teria se comportado se não tivesse falecido tão prematuramente. Mas o fato é que, inegavelmente, Mariátegui procurou unir - e, em grande medida, conseguiu - seu pensamento a uma prática política que respondesse às exigências do momento.

É possível que as raízes desta discrepância entre os dois autores se expliquem por diferenças em suas trajetórias políticas. Enquanto Caio Prado aderiu a um partido já constituído e cuja direção não valorizava muito o trabalho intelectual, Mariátegui não encontrou em seu país nenhum partido de esquerda formado, o que fez com que ele assumisse para si, na condição de liderança intelectual marxista, a tarefa de fundá-lo.

Por fim, há um último e decisivo aspecto que aproxima suas diferentes concepções da revolução: a busca de um programa de ação política calcado numa análise das condiçôes concretas de suas respectivas sociedades. Ambos consideraram, como se pode constatar ao longo deste artigo, a incompletude da formação de suas naçôes como eixo articulador dos programas revolucionários que defendiam.

Assim, se está diante daquela problemática proposta por Eric Hobsbawm ao tratar da história dos PCs: o difícil casamento entre uma forma de ação revolucionária internacional - o bolchevismo - e as tradições de uma esquerda nacional (Hobsbawm, 2003, p. 15). As obras do brasileiro e do peruano são tentativas de responder a esse desafio, ao partirem de uma matriz leninista para propor uma estratégia revolucionária adequada aos contextos nacionais.

\section{Conclusão}

À guisa de conclusão, é interessante retomar o problema mais geral exposto no início deste artigo: não obstante suas dificuldades de dar conta da especificidade latino-americana, o marxismo não deixou de produzir contribuições originais no subcontinente. Para Novais o marxismo propriamente latino-americano surge após a Revolução Cubana de 1959, por meio das distintas vertentes da teoria da dependência que se desenvolveram como crítica à economia política cepalina. Os precursores desse marxismo foram justamente, segundo ele, Caio Prado Jr. e José Carlos Mariátegui, cujas realizações teriam se destacado em meio à ortodoxia comunista prevalecente nos períodos em que atuaram (Novais, 1983, p. 25).

Caberia indagar, todavia, no que consiste a especificidade do marxismo dos dois autores, o que os diferencia das teorizações do movimento comunista ao qual pertenceram? O que procurei demonstrar aqui é que essa propalada originalidade de ambos os autores se explica pelo modo particular pelo qual os dois articularam o método de interpretação marxista e uma certa formulação da questão nacional. Foi justamente esta articulação que lhes deu a chave para produzirem interpretaçôes originais das realidades de seus países e da América Latina. Quanto ao sucesso político dessas interpretaçôes, este é outro problema que, nos limites deste artigo, só pode ser tangenciado.

Neste caso, é interessante retomar o problema, mencionado no início, da disputa entre marxistas e populistas. Tanto Mariátegui quanto Caio Prado tiveram movimentos populistas - como o aprismo ou o trabalhismo de origem varguista - como adversários diretos, caso do primeiro, ou indiretos, caso do segundo. As caracterizações que ambos fizeram do populismo, embora acompanhem as diferenças de tempo e lugar, possuem alguns traços comuns. Mariátegui sequer utilizava o termo, o qual ainda não ganhara o sentido que teria no vocabulário político latino-americano. $\mathrm{O}$ marxista peruano considerava o aprismo um movimento "nacionalista pequeno-burguês", com a confusão ideológica que caracterizaria essa classe social, tornando-a politicamente inconsequente. 
Outro traço que reprovava no aprismo era seu "personalismo" em torno de Haya que, como sustentou nas cartas à célula aprista do México, lembrava aspectos da "velha política criolla" (Mariátegui, 1991e, pp. 130-131).

O "personalismo" e a ausência de definição ideológica também marcam a caracterização de Caio Prado. Para ele o populismo resultava da combinação da democratização da vida política brasileira e da expansão da máquina estatal - a qual oferecia novas possibilidades de colocação para a classe média - que se desenvolveram a partir da Revolução de 30 e da Era Vargas:

Resultaram daí essas formações e correntes políticas genericamente conhecidas como populismo e que nada mais constituiriam de fato, apesar de suas aparências e designações, que um sistema de interesses personalistas mantidos à custa de favores do Estado e apoiados na força ascensional, dentro das instituições brasileiras, das camadas e forças populares (Prado Jr., 1960, pp. 3-4)

Embora reconhecesse o papel do populismo como canal de participação dos trabalhadores, essas palavras deixam claro o viés negativo com que o historiador paulista analisava o fenômeno, o que, aliás, coincide com as apreciações de Mariátegui com relação ao aprismo após a ruptura com Haya. As apreciações do peruano e do brasileiro - centradas na ambiguidade ideológica, no personalismo e na heterogeneidade social - deixam entrever aquela concepção societária da política que, segundo a hipótese já referida de Portantiero, teria obstaculizado ao marxismo latino-americano a compreensão do fenômeno do populismo.

Seja como for, quando se analisa a relação entre uma contribuição teórica e seus resultados políticos, é sempre útil lembrar que não há um vínculo direto e mecânico entre teoria e prática política. Isso fica bem ilustrado com a incapacidade de Caio Prado de propor, a partir de sua crítica historiográfica, uma estratégia política alternativa à do $\mathrm{PCB}$, ou pelo difícil equilíbrio que Mariátegui procurou manter entre o aprismo e a IC. Todavia, se a "boa teoria" nem sempre conduz à prática bem-sucedida, ela ao menos pode ajudar a evitar erros políticos. Se não é fácil dirimir o quanto o malogro de organizações, como o dos PCs brasileiro e peruano, se deve a seus equívocos teóricos, é certo, por outro lado, que sua inserção na política nacional foi dificultada pela excessiva fidelidade a fórmulas políticas pensadas para outras realidades. Trata-se, mais uma vez, da relação tensa - que por vezes se transformou em disjuntiva - entre o marxismo e a nação. Em todas as revoluções vitoriosas (como a cubana ou a chinesa), este problema teve de ser equacionado de uma ou outra maneira. Porém, como lembra Galindo, as revoluçōes vitoriosas foram casos excepcionais (Galindo, 1994, p. 385).

O legado deixado por Caio Prado Jr. e Mariátegui para o marxismo latino-americano é uma postura intelectual que prioriza não a fidelidade a determinados conceitos originais, mas a necessidade de compreender as particularidades da realidade social. Ambos partindo do marxismo de matriz comunista foram capazes de, ao priorizar o enraizamento nas condiçôes concretas de seus países, romper seus estreitos limites. Assim, as obras desses dois autores representaram passos importantes para que o pensamento de Karl Marx, o qual nunca se preocupou com a América Latina, pudesse fazer sentido na região.

\section{Notas}

1 Para a bibliografia que sugere a comparação entre Caio Prado Jr. e Mariátegui, da qual retirei as hipóteses seguintes, ver Novais (1983, p. 25), Ricupero (2000, pp. 62-92) e Coutinho (1989, pp. 116-132).

2 A maioria dos comentadores da obra de Caio Prado aponta para a discrepância entre a qualidade de sua contribuição como historiador e a relativa pobreza de seu arsenal categorial marxista (Coutinho, 1989).

3 O termo indígena não comparece de modo adjetivo, já que, para Mariátegui, classe e cultura estavam intimamente embricadas. Se Caio Prado nunca deu um peso similar à questão racial, isso se deve, a meu ver, ao fato de que a fratura existente no Peru, bem como nas demais sociedades andinas, entre a população de origem indígena e a elite de extração europeia não tem qualquer paralelo no Brasil. 
4 O primeiro trabalho a considerar a economia brasileira como sendo mercantil desde seu princípio foi a História econômica do Brasil, do economista e empresário Roberto Simonsem. Este livro, publicado em 1937, é tido como o primeiro trabalho de história econômica mais consistente no país e exercerá influência sobre Caio Prado (Secco, 2008, pp. 169-170).

5 Joseph Love assinala que, antes de ser teoria, a industrialização na América Latina foi um fato concreto e, em seguida, uma política. Teria sido apenas com a Cepal, a partir de 1949, que os economistas encontraram uma base teórica alternativa ao velho conceito de "vantagens comparativas" (Love, 1996, pp. 210-217).

6 O Apra foi fundado por Haya de La Torre em 1924 na Cidade do México, onde o peruano se encontrava exilado. Inicialmente concebida como frente anti-imperialista, o movimento teve a colaboração dos comunistas até 1927, quando há a ruptura entre seu líder e a IC. Mariátegui ainda tentou manter relações com Haya até o ano seguinte, quando rompeu com os apristas pela iniciativa de Haya de La Torre de converter o Apra em partido político (Montesinos, 2002, pp. 34-35; Quijano, 1991, p. 122). Após a morte de Mariátegui (1930), o PARA firmar-se-ia como principal partido de massas do Peru, e Haya de La Torre, embora nunca tenha chegado ao poder, exerceria grande influência sobre a vida política de seu país até sua morte, em 1979.

7 Leguía chegou ao poder no Peru em 1919, na esteira de mobilizações estudantis e operárias em Lima que puseram fim ao monopólio do poder da oligarquia tradicional, agrupada no Partido Civil. Quatro anos mais tarde, o regime leguista daria uma guinada conservadora e autoritária. Seu governo caracterizava-se por uma tentativa de impulsionar o desenvolvimento econômico e a centralização do poder estatal com base em uma política de empréstimos estrangeiros. Leguía foi deposto por um golpe militar em 1930, abalado pela crise de 1929.

\section{BIBLIOGRAFIA}

ARICÓ, J. (1982), Marx e a América Latina. Rio de Janeiro, Paz e Terra.

(1978), “Introducción”, in (org.), Mariátegui y los origenes del marxismo latino-americano. México, DF, Pasado y Presente.
BRANDÃO, G. M. (1997), A esquerda positiva: as duas almas do Partido Comunista (1920-1964). São Paulo, Hucitec. (2007), Linhagens do pensamento político brasileiro. São Paulo, Hucitec.

BRESSER-PEREIRA, L. C. (1979), "Seis interpretações sobre o Brasil”. Dados, 3 (5).

CABALLERO, M. (1988), La Internacional Comunista y la revolución latino-americana. Caracas, Nueva Sociedad.

CÂNDIDO, A. (1965), Literatura e sociedade. São Paulo, Companhia Editora Nacional.

COUTINHO, C. N. (1985), "As categorias de Gramsci e a realidade brasileira", in C. N. Coutinho e M. A. Nogueira (orgs.), Gramsci e a América Latina, Rio de Janeiro, Paz e Terra. (1989), “Uma via 'não-clássica’ para o capitalismo", in M. A. Dincao (org.), História e ideal: ensaios sobre Caio Prado Jr., São Paulo, Brasiliense/Editora da Unesp.

DONGHI, T. H. (s.d.), História da América Latina. São Paulo, Círculo do Livro.

FAUSTO, R. (1967), "A revolução brasileira de Caio Prado Jr". Teoria e Prática, 1 (2).

FEMIA, J. V. (1988), "Historicist methods for critique of revisionist studying of ideas", in J. Tully (org.), Meaning and context: Quentin Skinner and his critics, Oxford, Oxford University Press.

FUNES, P. (2006), Salvar la nación: intelectuales, cultura y política em los años 20 latino-americanos. Buenos Aires, Prometeo Libros.

FURTADO, C. (1962) Formação Econômica do Brasil. São Paulo, Companhia Editora Nacional

GALINDO, A. F. (1994), "La agonia de Mariátegui: la polémica com la Comintern", in Obras Completas, Lima, Fundación Andina.

GALINDO, A. F. \& BURGA, M. (1994), "Apogeu y crisis de la república aristocrática", in Obras Completas, Lima, Fundación Andina.

GRAMSCI, A. (2002a), "Risorgimento", in , Cadernos do Cárcere, Rio de Janeiro, Civilização Brasileira. (2002B), "Maquiavel, a política e o Estado moderno", in ,Cadernos do Cárcere, Rio de Janeiro, Civilização Brasileira. 
HAYA DE LA TORRE, V. R. (2002a), "El aprismo és uma doctrina completa y un método de acción realista”, in J. N. Montesinos (org.), Haya de la Torre o la política como missión civilizadora, México, DF, Fondo de Cultura Económica. . (2002b), "El Estado anti-imperialista", in J. N. Montesinos (org.), Haya de la Torre o la política como missión civilizadora, México, DF, Fondo de Cultura Económica.

HOBSBAWM, E. J. (2003), Revolucionários: ensaios contemporâneos. Rio de Janeiro, Paz e Terra

LÊNIN, V. I. (1986), "As duas táticas da social-democracia na revolução democrática", in Obras Escolhidas, São Paulo, Alfa-Ômega.

LOVE, J. (1996), "Economic ideas and ideologies in Latin America since 1930", in L. Bethell (org.), Ideas and ideologies in 20th Century Latin America, Cambridge, Cambridge University Press.

LÖWY, M. (1999), O marxismo na América Latina. São Paulo, Fundação Perseu Abramo.

MARIÁTEGUI, J. C. (1991a), "Respuesta al questionário no. 4 del Seminário de Cultura Peruana", in A. Quijano (org.), Textos básicos, México, DF, Fondo de Cultura Económica.

(1991B), "Punto de vista anti-imperialista", in A. Quijano (org.), Textos básicos, México, DF, Fondo de Cultura Económica.

(1991C), "El problema de las razas em América Latina”, in A. Quijano (org.), Textos básicos, México, DF, Fondo de Cultura Económica. (1991D), "Aniversário y balance", in A. Quijano (org.), Textos básicos, México, DF, Fondo de Cultura Económica.

. (1991E), "Carta a la célula aprista de México”, in A. Quijano (org.), Textos básicos, México, DF, Fondo de Cultura Económica.

. (1995), "Réplica a Luiz Alberto Sánchez", in , Mariátegui Total, Lima, Amauta.

. (2008), Siete ensayos de interpretación de la realidade peruana. Caracas, Biblioteca Ayacucho.

MELLIS, A. (1978), "Mariátegui: el primer marxista de América”, in J. Aricó (org.), Mariátegui y los origenes del marxismo latino-americano, México, DF, Pasado y Presente.
MONTESINOS, J. N. (2002), "Estúdio introductorio", in (org.), Haya de la Torre o la politica como missión civilizadora. México, DF, Fondo de Cultura Económica.

NOVAIS, F. A. (1983), "Caio Prado Jr. na historiografia brasileira”, in R. Antunes, V. Ferrante e R. Moraes (orgs.), Inteligência brasileira, São Paulo, Brasiliense.

PARIS, R. (1980), La formación ideológica de José Carlos Mariátegui. México, DF, Pasado y Presente.

PORTANTIERO, J. C. (1978), "Los usos de Gramsci”, in A. Gramsci, Escritos políticos, México, DF, Pasado y Presente.

(1985), "O nacional-popular: Gramsci em chave latino-americana", in C. N. Coutinho e M. A. Nogueira (orgs.), Gramsci e a América Latina, Rio de Janeiro, Paz e Terra.

PRADO JR., C. (1954), Diretrizes para uma politica econômica brasileira. São Paulo, Urupês.

(1955), "Nacionalismo brasileiro e capitais estrangeiros”. Revista Brasiliense, 1 (2). . (1957), Formação do Brasil contemporâneo (Colônia). São Paulo, Brasiliense.

. (1959), "Os empreendimentos estrangeiros e o desenvolvimento nacional”. Revista Brasiliense, 5 (23).

. (1960), "As eleições de 3 de outubro". Revista Brasiliense, 6 (32).

- (1966), A revolução brasileira. São Paulo, Brasiliense.

- (1987), Evolução política do Brasil e outros estudos. São Paulo, Brasiliense.

. (2000), A questão agrária no Brasil. São Paulo, Brasiliense. (2002), História econômica do Brasil. São Paulo, Brasiliense.

. (2007), "Fundamentos econômicos da revolução brasileira”, in R. Santos (org.), Dissertações sobre a revolução brasileira, São Paulo, Brasiliense/Fundação Astrogildo Pereira.

QUIJANO, A. (1991), "Nota introductória", in (org.), Textos básicos, México, DF,

Fondo de Cultura Económica.

RICUPERO, B. (2000), Caio Prado Jr. e a nacionalização do marxismo no Brasil. São Paulo, Editora 34. 
SANTOS, R. (2001), Caio Prado Jr. na cultura politica brasileira. Rio de Janeiro. Mauad/Faperj.

SECCO, L. (2008), Caio Prado Jr: o sentido da revolução. São Paulo, Boitempo

SCHLESSINGER, R. (1974), La Internacional Comunista y el problema colonial. México, DF, Pasado y Presente.

SKINNER, Q. (1974), "Some problems in the analysis of political thought and action". Political Theory, 2 (3).

TAVARES, A. (1967), "Caio Prado Jr. e a teoria da revolução brasileira”. Encontros com a civilização brasileira, 1, Rio de Janeiro, Civilização Brasileira.

TULLY, J. (1988), “The pen is a mighty sward”, in (org.), Meaning and context: Quentin Skinner and his critics, Oxford, Oxford University Press. 


\section{OS DILEMAS DO MARXISMO LATINO-AMERICANO NAS OBRAS DE CAIO PRADO JR. E JOSÉ CARLOS MARIÁTEGUI}

André Kaysel

Palavras-chave: Caio Prado Jr.; José Carlos Mariátegui; Marxismo; Questão nacional; América Latina.

O objetivo deste artigo é comparar a relação entre o marxismo e a questão nacional nas obras do historiador brasileiro Caio Prado Jr. e do jornalista e militante peruano José Carlos Mariátegui. Parto da hipótese de que ambos compartilham uma leitura análoga da questão nacional, entendida como formação inconclusa da nação, obstaculizada pela persistência do legado colonial. Para tanto, discuto as proximidades e as discrepâncias entre os dois autores por meio de um cotejo de suas obras em torno de cinco problemas comuns: passagem colônia/nação; questão agrária; relação como o imperialismo; burguesia nacional; teoria da revolução. Com esse esforço interpretativo, pretendo demonstrar como ambos contribuíram para superar as dificuldades do marxismo em compreender as realidades latino-americanas.

\section{DILEMAS OF LATIN-AMERICAN MARXISM IN THE WORKS OF CAIO PRADO JR. AND JOSÉ CARLOS MARIÁTEGUI}

André Kaysel

Keywords: Caio Prado Jr.; José Carlos Mariátegui; Marxism; the National Question; LatinAmerica.

The aim of this paper is to compare the relationship between Marxism and the national question in the works of Brazilian historian Caio Prado Jr. and Peruvian journalist and activist José Carlos Mariátegui. Based on the assumption that both share a similar reading of the national question - understood as the nation's unfinished formation, hampered by the persistence of the colonial legacy -, the article discusses the proximities and discrepancies between the two authors through a comparison of their works around some problems treated by both of them: the passage colony/nation, the agrarian question, the relationship between imperialism and the national bourgeoisie, and the theory of revolution. With such interpretative effort, one intends to demonstrate how both authors helped to overcome the difficulties of the Marxist theory for the understanding Latin-American realities.

\section{LES DILEMMES DU MARXISME LATINO-AMÉRICAIN DANS LES GEUVRES DE CAIO PRADO JR. ET DE JOSE CARLOS MARIATEGUI}

André Kaysel

Mots-clés: Caio Prado Jr.; José Carlos Mariátegui; Marxisme; Question nationale; Amérique Latine.

Le but de cet article est de comparer la relation entre le marxisme et la question nationale dans les travaux de l'historien brésilien Caio Prado Jr. et du journaliste et militant péruvien Jose Carlos Mariategui. Je pars de l'hypothèse selon laquelle les deux partagent une lecture similaire de la question nationale, comprise comme étant la formation inachevée de la nation, entravée par la persistance de l'héritage colonial. Je discute, ainsi, les proximités et les divergences entre les deux auteurs grâce à une comparaison des cinq problèmes communs à leurs œuvres: le passage colonie/nation; la question foncière; la relation avec l'impérialisme; la bourgeoisie nationale; et la théorie de la révolution. Fondé sur cet effort d'interprétation, j'ai l'intention de démontrer comment ils ont aidé à surmonter les difficultés du marxisme pour comprendre les réalités de l'Amérique Latine. 